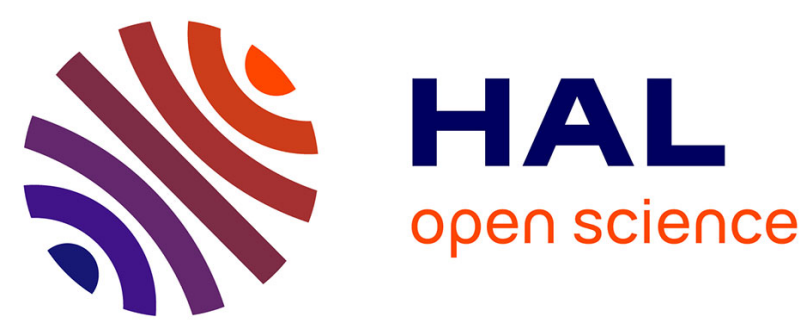

\title{
Enrichment of the light-harvesting complex in diadinoxanthin and implications for the non-photochemical fluorescence quenching in diatoms
}

Johann Lavaud, Bernard Rousseau, Anne-Lise Etienne

\section{- To cite this version:}

Johann Lavaud, Bernard Rousseau, Anne-Lise Etienne. Enrichment of the light-harvesting complex in diadinoxanthin and implications for the non-photochemical fluorescence quenching in diatoms. Biochemistry, 2003, 42, pp.5802-5808. 10.1021/bi027112i . hal-01094160

\section{HAL Id: hal-01094160 \\ https://hal.science/hal-01094160}

Submitted on 11 Dec 2014

HAL is a multi-disciplinary open access archive for the deposit and dissemination of scientific research documents, whether they are published or not. The documents may come from teaching and research institutions in France or abroad, or from public or private research centers.
L'archive ouverte pluridisciplinaire HAL, est destinée au dépôt et à la diffusion de documents scientifiques de niveau recherche, publiés ou non, émanant des établissements d'enseignement et de recherche français ou étrangers, des laboratoires publics ou privés. 


\section{Enrichment of the light-harvesting complex in}

\section{diadinoxanthin and implications for the non-}

\section{photochemical fluorescence quenching in diatoms ${ }^{\dagger}$}

${ }^{\dagger}$ J. L. thanks the French Ministry of Education, Research and Technology for financial support.

Johann Lavaud*, Bernard Rousseau and Anne-Lise Etienne

Laboratoire 'Organismes Photosynthétiques et Environnement', UMR CNRS 8543, Ecole Normale Supérieure, 46 rue d’Ulm, 75230 Paris Cedex 05, France

E-mail: lavaud@biologie.ens.fr

*To whom correspondence should be addressed: Laboratoire 'Organismes Photosynthétiques et Environnement', UMR CNRS 8543, Ecole Normale Supérieure, 46 rue d'Ulm 75230 Paris Cedex 05, France. E-mail: lavaud@biologie.ens.fr. Phone: +3314432 35 30. Fax: +3314432 3935

Running title: Diadinoxanthin enrichment in diatoms 
${ }^{1}$ Abbreviations: Chl, chlorophyll; CL, continuous light regime (16 h light/8 h dark per day); DD, diadinoxanthin; DT, diatoxanthin; IL, intermittent light regime (5 min light per hour); LHC, Lightharvesting complex; LHCF, Light-harvesting complex containing Fucoxanthin; NPQ, nonphotochemical chlorophyll fluorescence quenching; PS II and I, photosystem II and I. 
The pigment composition of diatoms differs from that of green algae and plants. Diatoms contain chlorophyll $\left(\mathrm{Chl}^{1}\right) c$, fucoxanthin and diadinoxanthin (DD). An intermittent light regime during growth induced a large increase in the DD content in the marine planktonic diatom Phaeodactylum tricornutum. Light-harvesting complex (LHCF) subunits were purified on a sucrose gradient after treatment of thylakoid membranes with a mild detergent. DD was found all the LHCF fractions: a 'major' composite LHCF fraction and the two fractions where some LHCF was associated with photosystem centers. For cells enriched in DD, most of the additional DD molecules were bound to the major LHCF fraction. The DD enrichment of the major LHCF fraction was accompanied by a decrease in the fucoxanthin to Chl $a$ ratio. Either some fucoxanthin molecules were replaced by DD or there could be a relative enrichment of subunits rich in DD at the expense of fucoxanthin/Chl $c$ rich subunits. Under high light illumination, a higher degree of de-epoxidation of DD into DT was observed for the major LHCF of cells enriched in DD. This fraction has the higher DD content and the higher degree of de-epoxidation. These results show that the distal antennae, probably mostly isolated as the major LHCF fraction, plays a crucial role in the formation of NPQ, its amplitude depending on the amount of DD bound and on the degree of deepoxidation [Lavaud et al. (2002) Plant Physiology 129, 1398-1406]. 
Diatoms are unicellular photosynthetic eukariots which play a key role in the ocean carbon, silica and azote cycles $(1,2)$. They are ubiquitous and the major group of phytoplanktonic marine algae. They experience large fluctuations in light intensity due to unpredictable water motions that can vary over several orders of magnitudes (3-5). As other photosynthetic organisms $(6,7)$, they have developed efficient photoprotective mechanisms (8-13) in order to minimize photoinhibition that could result from their periodic exposure to excess light intensities when transported to the water column surface (14). Among the short term 'safety valves' which are activated by a sudden increase in light intensity, the photoprotective non-radiative dissipation of the light energy absorbed in excess is an important mechanism (15). This phenomenon is attributed to rapid modifications within the light-harvesting complexes (LHC) of photosystem II (PS II) leading to a decrease in the excitation pressure on PS II (16, 17). It is designated as the non-photochemical fluorescence quenching (NPQ) process and measured by a decrease in chlorophyll (Chl) fluorescence intensity under high light. In higher plants and green algae, NPQ is controlled by the formation of a proton gradient across the thylakoid membrane and by reversible conversion of epoxidized (violaxanthin) to de-epoxidized (antheraxanthin and zeaxanthin) forms of xanthophylls (the so-called xanthophyll cycle, for reviews see refs (16-20)). In diatoms, the xanthophyll cycle consists in the conversion of the mono-epoxide diadinoxanthin (DD) into the deepoxide diatoxanthin (DT) under excess light, and vice-versa under limiting light or darkness (21). The formation of DT is associated with the onset of NPQ within the light-harvesting complexes (LHCF) (9, $11,12,22)$. In higher plants, the location and cycling of xanthophylls within LHC subunits have been the subject of many investigations (see refs (23-25) and citations within). It has been shown recently that in higher plants, a specific LHC subunit, the CP22 (PsbS), binds zeaxanthin in vitro (26). It plays a crucial role in NPQ: the Arabidopsis psbS deletion mutant is not capable of NPQ (27) and there is a stoichiometric dependence of NPQ capacity on the amount of PsbS $(28,29)$.

There is a lack of knowledge concerning the exact nature and organization of LHCF subunits in diatoms, and especially the location of DD and DT in the antenna complex. The whole organization of the photosynthetic apparatus in diatoms differs in many aspects from that of green plants: i) their 
pigment composition is different, with Chl $c$ and fucoxanthin as the main xanthophyll, ii) the xanthophyll concentration relative to Chl can be two to four times higher than in higher plants $(30,31)$, and iii) there is no grana stacking and no segregation of PS II and PS I (32). LHCF subunits are made of several highly homologous proteins encoded by a multigene family (Fucoxanthin Chlorophyll Proteins, FCP, (33)). No obvious orthologs of some of the important components of LHC of higher plants PS II (e. g. the minor antennae CP 26, CP 29 and PsbS) have been found in Phaeodactylum tricornutum Böhlin or within the genome sequence of Thalassiosira pseudonana Hustedt (Hasle and Heimdal) (17), C. Bowler, personal com.).

It is known that the DD content of diatoms can be modulated by the light regime during culturing (34-36). We used an intermittent light regime to grow the marine planktonic diatom P. tricornutum. As a result there was a specific increase in the DD content of cells. The additional DD was convertible to DT under excess light exposure of whole cells and concomitantly photoprotective energy dissipation was increased (12).

In the present study, our goal was to locate the DD molecules and determine their degree of conversion into DT within the different pigment-protein complexes. We present the pigment content and spectroscopic properties of LHCF fractions isolated from $P$. tricornutum cells grown under an intermittent light regime, and compare them with those of cells grown under a 'classical' light regime which have a smaller DD content. The data obtained provide a possible explanation for the larger NPQ found in cells enriched in DD (12).

\section{MATERIALS AND METHODS}

\section{Cultures.}

Phaeodactylum tricornutum Böhlin (from the algal culture collection of Laboratoire Arago, Banyuls, France) cells were grown photoautotrophically in sterile natural seawater F/2 medium (37). Cultures of $300 \mathrm{~mL}$ were incubated at $18{ }^{\circ} \mathrm{C}$ in airlifts continuously flushed with sterile air. They were illuminated at a light intensity of $40 \mu \mathrm{mol}$ photons. $\mathrm{m}^{-2} \cdot \mathrm{s}^{-1}$ with white fluorescent tubes (Claude, Blanc Industrie, 
France) with a $16 \mathrm{~h}$ light/8 h dark cycle for continuous light (CL) cells, or with a 5 min light/55 min dark cycle for intermittent light (IL) cells. The growth rate under IL illumination was reduced from $0.65 \mathrm{~d}^{-1}$ to $0.065 \mathrm{~d}^{-1}$, partly because of the 8 -fold lower total amount of light supplied. CL cells were collected after 3-4 days and IL cells between 30-40 days after dilution. Part of the culture was then diluted in fresh medium to maintain cells in exponential growth phase.

\section{Pigment content.}

Pigment analyses were performed by HPLC as described previously (11). Cells were filtered onto a filter paper (Millipore AP-20 prefilter) rapidly frozen into liquid nitrogen. After thawing, the filter was placed in a methanol:acetone solution $(70: 30, \mathrm{v} / \mathrm{v})$ to extract the pigments. For the light-harvesting complexes isolated on the sucrose gradient, pigments were extracted by a phase separation procedure: samples were first mixed with a methanol:acetone $(50: 50,1 \mathrm{v})$ solution completed with ether $(1 \mathrm{v})$ and water-NaCl $10 \%(2 \mathrm{v})$. Published extinction coefficients for chlorophylls (38) and for diadinoxanthin (DD) and diatoxanthin (DT) (39) were used. Cell counts were performed with a Thoma hematocymeter, using the public domain NIH Image program (US National Institute of Health).

\section{Spectroscopy.}

$77 \mathrm{~K}$ absorption spectra were performed with a DW-2 Aminco spectrophotometer equipped with a home-made Dewar holder. $77 \mathrm{~K}$ fluorescence excitation spectra were measured with a F-4500 Hitachi spectrophotometer. Half-bandwidth for emission and excitation was $2.5 \mathrm{~nm}$. Samples were dark-adapted and then concentrated on a Millipore AP-20 prefilter that was immediately frozen in liquid nitrogen before measurement.

\section{Isolation of light-harvesting complexes.}

The light-harvesting complexes subunits were isolated as described (31). Chloroplasts were extracted and suspended in a $50 \mathrm{mM}$ Hepes- $\mathrm{KOH}$ buffer ( $\mathrm{pH}$ 7.6) with $5 \mathrm{mM} \mathrm{MgCl} 2,2 \mathrm{mM} \mathrm{MnCl}, 10 \mathrm{mM} \mathrm{KCl}$, 
$6 \mathrm{mM} \mathrm{Na}_{2}$-EDTA, $5 \mathrm{mM}$ amino caproic acid, $0.6 \mathrm{M}$ sorbitol and protease inhibitors $(1 \mathrm{mM}$ phenylmethanesulfonylfluoride and $1 \mathrm{mM}$ benzamidine). They were disrupted in a French pressure cell, then resuspended in the same buffer, without sorbitol, in the presence of digitonin at a detergent/Chl $a$ ratio of 80:1 and incubated for $1 \mathrm{~h}$ at $4{ }^{\circ} \mathrm{C}$. The homogenate was loaded on top of a sucrose gradient (10$55 \%$ ) and centrifuged at $140000 \mathrm{x}$ g for $15 \mathrm{~h}$ at $4{ }^{\circ} \mathrm{C}$. The three bands obtained corresponded, from the bottom to the top of the gradient, to PS I and PS II enriched fractions with some LHCF remaining bound, and the major free LHCF band (see Results section for a detailed description). For preilluminated cells, epoxidation of DT into DD was prevented by keeping all fractions on ice and by a faster handling of the samples.

\section{RESULTS}

Ultrastructure, photosynthetic parameters and pigment content of the CL and IL cells.

Phaeodactylum tricornutum Böhlin cells were grown at low light intensity $\left(40 \mu \mathrm{mol}\right.$ photons. $\left.\mathrm{m}^{-2} \cdot \mathrm{s}^{-1}\right)$ under two different light regimes: a $16 \mathrm{~h}$ light/8 $\mathrm{h}$ dark cycle for 'continuous light' (CL) cultures and a 5 min light/55 min dark cycle for 'intermittent light' (IL) cultures. Cell size and chloroplast ultrastructure, as illustrated by the number of thylakoids and their organization, were similar under the two light regimes. The photosynthetic parameters of both types of cells have been previously described (12). They were all similar, especially photosystem stoichiometries, PS II antenna size and oxygen emission versus light intensity curve. The larger change in the pigment content of whole cells was that of DD which was more than twice in IL cells (Table 1). Fucoxanthin and Chl $c$ were decreased to a much lesser extent. At the low light intensity used for culturing, no DT was present before exposure of the cells to excess light (Table 1). DD absorbed in the blue region of the visible spectrum with a peak at $495 \mathrm{~nm}$ clearly visible in both the absorption spectra of cells enriched in DD (Fig. 1A, continuous line) and in the difference spectrum of the absorption spectra of cells with different DD content (Fig. 1A, bottom part). In the $77 \mathrm{~K}$ fluorescence excitation spectra of the fluorescence emission at $687 \mathrm{~nm}$ (characteristic of PS II), the contribution of $\mathrm{Chl} a, \mathrm{Chl} c$ and fucoxanthin to the transfer of excitation 
energy were visible (Fig. 1B). The contribution of DD was less marked showing that all DD molecules, and specifically the additional DD molecules in IL cells (Fig. 1B, arrow), would thus not be able to transmit their excitation energy to $\mathrm{Chl} a$.

Pigment content of the light-harvesting complexes of dark-adapted CL and IL cells.

After disruption of the chloroplasts of dark-adapted cells in presence of mild detergent, the homogenate was loaded onto a sucrose gradient and centrifuged. Three LHCF bands were obtained (Fig. 2A). The band on the top of the gradient (a brown band, at 10-15\% sucrose) contained $50 \%$ of the loaded Chl $a$ (Fig. 2B) and the majority of DD (Fig. 2C). The two other heavier bands contained 15$20 \% \mathrm{Chl} a$ each. This distribution is similar to what was observed when the same purification procedure was used with brown algae which belong to the same phylum (Heterokontophyts) $(40,41)$. The three bands obtained in P. tricornutum can be identified as follows. The top band corresponds to a band enriched in LHCF designated as the 'major' LHCF (Fig. 2A). In brown algae, it is quasi devoid of photosystems reaction centers $(31,42)$. According to $(38)$ and $(43)$, the two other bands are enriched in photosystems with their respective LHCF. In the present study, the intermediate band at $20 \%$ sucrose is enriched in PS II and the bottom band in PS I (Fig. 2A). Pellets represented 15-20\% of the total loaded Chl $a$ (Fig. 2B) and their pigment content was similar for both types of cells as shown in Table 1. This similarity in the pigment content of the pellets is important for valuable comparison of LHCF subunits pigment content of CL and IL cells.

It is known that the core complexes of the two photosystems contain only Chl $a$ and $\beta$-carotene. Therefore, proportionally to $\mathrm{Chl} a \mathrm{Chl} c$ and fucoxanthin were more abundant in the major LHCF fraction than in the fractions enriched in PS I and PS I core complexes (Table 1). The situation was reversed for $\beta$-carotene which is more abundant in the fractions enriched in photosystems. The traces of $\beta$-carotene in the major LHCF were indicative of a small contamination as already reported for isolation of LCH-II in higher plants (24). When comparing the DD/Chl $a$ in whole cells and in different fractions 
for IL and CL cells, it is obvious that the main enrichment in DD, when the DD pool was increased (IL cells), was in the major LHCF fraction (Table 1, Fig. 2C).

\section{Spectroscopic properties of the light-harvesting complexes of dark-adapted CL and IL cells.}

The $77 \mathrm{~K}$ absorption spectra of the major LHCF and the two photosystems fractions in the two types of cells are shown Figure 3. The spectra of the major LHCF fractions differed. The enrichment in DD of the major LHCF fraction of IL cells was clearly visible by the increased $495 \mathrm{~nm}$ peak (Fig. 3B, arrow). The spectra of PS II and PS I fractions of both types of cells were quite similar. They showed a smaller absorption in the blue region, as compared to the major LHCF fraction, indicative of a decrease in Chl $c$, fucoxanthin and DD content. The two photosystem fractions have also a larger concentration in long wavelength Chl $a$ than the major LHCF fractions.

The $77 \mathrm{~K}$ fluorescence emission of the major LHCF of CL and IL cells was maximal at $678 \mathrm{~nm}$ with a secondary peak at $735 \mathrm{~nm}$ (Fig. 4A). The small fluorescence at $635 \mathrm{~nm}$ showed that the majority of Chl $c$ molecules still transferred excitation energy to Chl $a$ and were not fluorescing. In this context, it is noticeable that the difference already observed in the Chl $c$ content in the major LHCF of the two types of cells was not due to an increase in free pigments in IL cells but reflected the difference observed between whole cells (Table 1). When comparing the $77 \mathrm{~K}$ excitation spectra of the emission at $678 \mathrm{~nm}$ (maximum emission of the major LHCF fractions) of whole cells and major LHCF of the two types of cells, one can see a large band in the 500-550 nm range in the LHCF fractions, which showed that most of the fucoxanthin molecules remained correctly bound and transferred their excitation energy to Chl $a$ (Fig. 4B). It was not the case for the DD molecules which contribution around $495 \mathrm{~nm}$ was no longer detectable especially for $\mathrm{IL}$ cells (compare Fig. 1B and Fig. 4B). However, the fact that the DD absorption peak was not blue-shifted after purification of LHCF (Fig. 3) is a possible indication that DD remained connected to complexes, as already reported for the analogue violaxanthin (44), but probably not in a configuration that still allowed energy transfer to Chl $a$ as observed for whole cells (Fig. 1B). Hence, considering that free pigments are a minority (no free pigments were visible on the top of the 
sucrose gradient, Fig. 2A) one can further analyze the pigment content of LHCF fractions (Table 2). The pigment content of the two major LHCF fractions was different. There was significantly less fucoxanthin and Chl $c$ but more DD in the IL fraction. However, the xanthophyll (fucoxanthin+DD) to Chl $a$ ratio as well as the ratio $\mathrm{Chl} c /$ fucoxanthin remained constant.

Pigment content and spectroscopic properties of the light-harvesting complexes of illuminated IL cells.

With the low light intensity used for culturing, no DT was present in whole cells (Table 1). When cells were shifted to excess light, the de-epoxidation of DD into DT took place (22). We have previously shown that under excess light, the degree of de-epoxidation was higher in IL cells, resulting in a larger accumulation of DT (22). For a light intensity of $2000 \mu \mathrm{mol}$ photons. $\mathrm{m}^{-2} \cdot \mathrm{s}^{-1}$ during $1 \mathrm{~h}$, the amount of DT formed was 5 and $12.5 \mathrm{~mol} \mathrm{DT} / 100 \mathrm{~mol} \mathrm{Chl} a$ in CL and IL cells, respectively. It corresponded to a de-epoxidation degree of $50 \%$ and $65 \%$ respectively (12).

In order to determine the degree of de-epoxidation in the three LHCF fractions in IL cells, they were strongly illuminated during 20 min prior to purification of the fractions. When comparing the pigment content of dark-adapted and illuminated cells, one can observed that during illumination, the amount of all pigments remained constant with a small increase in the sum DD+DT due to a slight de novo synthesis of DT (9). While the major LHCF fraction showed a degree of de-epoxidation similar to whole cells, the degree was clearly less in the two photosystems fractions (Table 2): the amount of DT reached in the major LHCF fraction was three times that reached in the PS+LHCF fractions. The conversion of DD into DT was illustrated by peaks at 438, 474 and $508 \mathrm{~nm}$ in the difference absorption spectrum of the major LHCF of illuminated cells minus dark-adapted cells (Fig. 6). The $508 \mathrm{~nm}$ peak has already been assigned to DT (45). The three bands are very similar to those observed in the zeaxanthin-minusviolaxanthin difference spectrum in higher plants (46). 


\section{DISCUSSION}

Additional DD binds to the 'major' light-harvesting complex in DD enriched cells.

In P. tricornutum, the size of the DD pool increases under intermittent light and a larger fraction of the pool is susceptible to de-epoxidation $(12,22)$. It was important to determine the exact location of the additional DD molecules in the IL cells. Indeed, the corresponding DT molecules produced under high light were shown to enhance the dissipation of excess energy and were therefore likely to be bound to the antenna subunits responsible for the NPQ process (12).

In brown algae which belong to the same phylum than diatoms, it has been shown that a LHCF monomer can contain seven Chl $a$ and as much as height fucoxanthin molecules $(41,42)$. Nothing is known about the number of violaxanthin (the analogue of DD in brown algae) bound per subunit. After solubilization of the $P$. tricornutum thylakoids membranes by a mild detergent and fractionation of the pigment-protein complexes, all the fractions containing LHCF antenna are found to contain DD as reported for its violaxanthin analog in higher plants $(24,47)$. In IL cells, compared to CL cells, nearly all of the additional DD molecules are bound to the major composite LHCF fraction with only a minor enrichment for the LHCF fractions which remain associated with the photosystem centers. Two hypotheses can be proposed to explain the quasi specific DD enrichment of the major composite LHCF fraction in IL cells. The first could be a pigment-pigment 'replacement'. If we assume that the Chl $a$ stoichiometry of LHCF subunit in diatoms is the same than in brown algae, we can estimate that in IL cells one subunit would bind two DD molecules. In CL cells, only one DD would be bound per LHCF subunit. Such a doubling of the DD amount bound to one LHCF subunit would be explained by a replacement of some fucoxanthin molecules by DD. This is supported by the observation that the enrichment in DD in IL cells is correlated with a stoichiometric parallel decrease in fucoxanthin (Table 3). Such a "competition" of two xanthophylls of related structures, as it is the case for DD and fucoxanthin $(48,49)$, for a common binding site is conceivable. In higher plants, the possibility that a given site of a LHC protein can bind different xanthophylls has been demonstrated both in vitro (20) and in vivo $(25,50,51)$. However, the existence of LHCF subunits with different pigment content is very 
likely. Since, in parallel to the increase in DD content, Chl $c$ decreases in the same extent as fucoxanthin, some subunits could be specifically rich in DD while others could mainly bound fucoxanthin and Chl $c$. The relative abundance of the different subunits would be modulated by light. It has already been shown that the expression of the different $l h c f$ genes is light-dependent $(52,53)$. The regulation of the LHCF protein synthesis has been studied as a function of light intensity (54-57) but not as a function of the light period. In IL cells, the amount of subunits rich in DD would be increased and that of subunits rich in fucoxanthin and $\mathrm{Chl} c$ decreased compared to the situation in CL cells.

Fucoxanthin, Chl $c$ and Chl $a$ are the main contributors of the energy harvesting (Fig. 1A) and transfer to the photosystem reaction centers (Fig. 1B). Therefore, the modulation in DD content allows the cells to regulate their capacity for dissipating energy under excess light without changing significantly the light-harvesting under limiting conditions.

\section{The xanthophyll cycle within light-harvesting complexes in DD enriched cells.}

Under excess light, a higher degree of de-epoxidation occurs in DD enriched cells $(12,22)$. To be deepoxidized, xanthophylls have to be accessible to the de-epoxidase which is localized in the lipid matrix (19). The fraction of DD which can be transformed to DT is thus likely located at the periphery of the pigment-protein complexes (25). The fact that DD is more abundant and de-epoxidized to a larger extent within the major LHCF of IL cells leads to propose a peripheral location for the additional DD molecules. Comparison of absorption and excitation spectra (Fig. 1) shows that part of additional DD molecules interact with Chl $a$ with a low efficiency. This could also suggests a peripheral location of these molecules. In brown algae, among the eight fucoxanthin molecules that one LHCF monomer can bind, two are proposed to have a role in the stabilization of the LHCF $(41,58)$ by analogy with the two central lutein molecules in the LCHII of higher plants (59). The binding sites of the six other molecules of fucoxanthin remain unknown. In the framework of our 'DD-fucoxanthin replacement hypothesis' and if we assume the same fucoxanthin stoichiometry per monomer in $P$. tricornutum, at least two fucoxanthin molecules could be bound at the periphery of the LHCF. Under intermittent light, these 
molecules would be likely to be the ones that could possibly be replaced by DD, then easily accessible to the de-epoxidase.

In a previous report, we have shown that NPQ is enhanced in IL grown cells and linearly related to the amount of DT formed upon light exposure (12). Our present results show that the majority of the additional DD molecules are bound to the major LHCF and that the largest degree of de-epoxidation is observed in this fraction. It indicates that NPQ mostly takes place in the distal antennae, essentially isolated as the major LHCF fraction. Similar conclusions were recently reached for higher plants (44, 60). Considering the most recent results on the understanding of the NPQ process in higher plants about the essential role of PsbS and the fact it can bind zeaxanthin (the analogue of DT) $(26,29)$, one can conclude that the orthologue of PsbS in diatoms (if it exists) is likely to be found in the composite major LHCF fraction.

\section{Concluding remarks}

By regulation of the light-harvesting through a fine-tuning of their xanthophyll content, diatoms are well suited to avoid the serious damages that may result from light stresses without any significant decrease in their capacity for light collection under light limiting conditions. As planktonic diatoms can modulate their DD pool size in the field (61-63), this ability likely explain their successful adaptation to the fluctuating light environment $(3,4)$.

Because DD de-epoxidation into DT can be readily observed by absorption changes (see Fig. 6), these changes will be used for further studies on the regulation of energy dissipation mechanism within the light-harvesting complexes. Such measurements have previously been performed with higher plants (64, 65). Intermittent light-grown diatoms being enriched in DD provide a unique model for further studies on photoprotective energy dissipation process. 


\section{AKNOWLEDGMENTS}

We thank C. Lichtlé for electron microscopic photographs of sections of diatom cells, J.-C. Thomas

for his assistance with spectroscopic measurements, A. Korber for artwork and Drs A. Ruban, A. Pascal and J. Houmard for critical reading and improvement of the manuscript. The paper is dedicated to J.-C. Duval, who initiated this work, for his sixtieth anniversary. 


\section{REFERENCES}

1. Field, C. B., Behrenfeld, M. J., Randerson, J. T., and Falkowski, P. (1998) Science 281, 237-40.

2. Smetacek, V. (1999) Protist 150, 25-32.

3. Harris, G. P. (1986) Phytoplankton Ecology: Structure, Function, and Fluctuation, Chapman \& Hall, London, UK.

4. Fogg, G. E. (1991) New Phytol. 118, 191-32.

5. Falkowski, P. G., and Raven, J. A. (1997) Aquatic Photosynthesis, Blackwell Science, Malden, USA.

6. Falkowski, P. G., and Laroche, J. (1991) J. Phycol. 27, 8-14.

7. MacIntyre, H. L., Kana, T. M., and Geider, R. J. (2000) Trends Plant Sci. 5, 12-17.

8. Ting, C. S., and Owens, T. G. (1993) Plant Physiol. 101, 1323-1330.

9. Olaizola, M., Laroche, J., Kolber, Z., and Falkowski, P. G. (1994) Photosynth. Res. 41, 357-70.

10. Ting, C. S., and Owens, T. G. (1994) Plant Physiol. 106, 763-770.

11. Arsalane, W., Rousseau, B., and Duval, J.-C. (1994) Photochem. Photobiol. 60, 237-43.

12. Lavaud, J., Rousseau, B., van Gorkom, H., and Etienne, A.-L. (2002) Plant Physiol. 129, 13981406.

13. Lavaud, J., van Gorkom, H., and Etienne, A.-L. (2002) Photosynth. Res. 74, 49-57.

14. Long, S., Humphries, S., and Falkowski, P. (1994) Ann. Rev. Plant Physiol. Plant Mol. Biol. 45, 633-62.

15. Niyogi, K. K. (2000) Curr. Opin. Plant Biol. 3, 455-60.

16. Horton, P., Ruban, A. V., and Walters, R. G. (1996) Annu. Rev. Plant Physiol. Plant Mol. Biol. $47,655-84$.

17. Müller, P., Li, X.-P., and Niyogi, K. K. (2001) Plant Physiol. 125, 1558-66.

18. Pfundel, E., and Bilger, W. (1994) Photosynth. Res. 42, 89-109.

19. Eskling, M., Arvidsson, P. O., and Akerlund, H. E. (1997) Physiol. Plantarum 100, 806-16.

20. Bassi, R., and Caffarri, S. (2000) Photosynth. Res. 64, 243-56. 
21. Hager, A., and Stransky, H. (1970) Arch. Mikrobiol. 73, 77-89.

22. Lavaud, J., Rousseau, B., and Etienne, A.-L. (2002) FEBS Lett. 523, 163-166.

23. Ruban, A. V., Young, A. J., Pascal, A. A., and Horton, P. (1994) Plant Physiol. 104, 227-234.

24. Färber, A., Young, A. J., Ruban, A. V., Horton, P., and Jahns, P. (1997) Plant Physiol. 115, 1609-1618.

25. Ruban, A. V., Lee, P. J., Wentworth, M., Young, A. J., and Horton, P. (1999) J. Biol. Chem. 274, 10458-10465.

26. Aspinall-O'Dea, M., Wentworth, M., Pascal, A., Robert, B., Ruban, A., and Horton, P. (2002) Proc. Natl. Acad. Sci. USA 99, 16331-16335.

27. Li, X. P., Bjorkman, O., Shih, C., Grossman, A. R., Rosenquist, M., Jansson, S., and Niyogi, K. K. (2000) Nature 403, 391-395.

28. Li, X.-P., Gilmore, A. M., and Niyogi, K. K. (2002) J. Biol. Chem. 277, 33590-33597.

29. Li, X.-P., Müller-Moulé, P., Gilmore, A. M., and Niyogi, K. K. (2002) Proc. Natl. Acad. Sci. USA 99, 15222-15227.

30. Wilhelm, C. (1990) Plant Physiol. Biochem. 28, 293-306.

31. Passaquet, C., Thomas, J. C., Caron, L., Hauswirth, N., Puel, F., and Berkaloff, C. (1991) FEBS Lett., 21-26.

32. Pyszniak, A. M., and Gibbs, S. P. (1992) Protoplasma 166, 208-17.

33. Bhaya, D., and Grossman, A. R. (1993) Nucleic Acids Res. 21, 4458-66.

34. Willemoës, M., and Monas, E. (1991) Physiol. Plantarum 83, 449-56.

35. Casper-Lindley, C., and Bjorkman, O. (1998) Photosynth. Res. 56, 277-89.

36. Mouget, J.-L., Tremblin, G., Morant-Manceau, A., Morançais, M., and Robert, J.-M. (1999) Eur. J. Phycol. 34, 109-115.

37. Guillard, R. R. R., and Ryther, J. H. (1962) Gran. Can. J. Microbiol. 8, 229-38.

38. Berkaloff, C., Caron, L., and Rousseau, B. (1990) Photosynth. res. 23, 181-93.

39. Johansen, J. E., Wa, S., Liaaen-Jensen, S., and Haxo, F. T. (1974) Phytochem. 13, 2261-71. 
40. Caron, L., Dubacq, J.-P., Berkaloff, C., and Jupin, H. (1985) Plant Cell Physiol. 26, 131-139.

41. De Martino, A., Douady, D., Quinet-Szely, M., Rousseau, B., Crépineau, F., Apt, K. E., and Caron, L. (2000) Eur. J. Biochem. 267, 5540-5549.

42. De Martino, A., Douady, D., Rousseau, B., Duval, J. C., and Caron, L. (1997) Photochem. Photobiol. 66, 190-197.

43. Douady, D., Rousseau, B., and Berkaloff, C. (1993) FEBS Lett. 324, 22-26.

44. Ruban, A. V., Pascal, A. A., Lee, P. J., Robert, B., and Horton, P. (2002) J. Biol. Chem. 277, 42937-42942.

45. Olaizola, M., and Yamamoto, H. Y. (1994) J. Phycol. 30, 606-12.

46. Yamamoto, H. Y., Kamite, L., and Wang, Y.-Y. (1972) Plant Physiol. 49, 224-228.

47. Lee, A. I., and Thornber, J. P. (1995) Plant Physiol. 107, 565-74.

48. Lohr, M., and Wilhelm, C. (1999) Proc. Natl. Acad. USA 96, 8784-8789.

49. Lohr, M., and Wilhelm, C. (2001) Planta 212, 382-91.

50. Pascal, A. A., Gradinaru, C., Wacker, U., Peterman, E., Calkoen, F., Irrgang, K.-D., Horton, P., Renger, G., van Grondelle, R., Robert, B., and van Amerongen, H. (1999) Eur. J. Biochem. 262, 817-823.

51. Baroli, I., and Niyogi, K. K. (2000) Phil. Trans. R. Soc. Lond. B 355, 1385-1394.

52. Apt, K. E., Clendennen, S. K., Powers, D. A., and Grossman, A. R. (1995) Mol. Gen. Genet. $246,445-464$.

53. Leblanc, C., Falciatore, A., Watanabe, M., and Bowler, C. (1999) Plant Mol. Biol. 40, 10311044.

54. Owens, T. G., and Wold, E. R. (1986) Plant Physiol. 80, 732-38.

55. Friedman, A. L., and Alberte, R. S. (1986) Plant Physiol. 80, 43-51.

56. Smith, B. M., and Melis, A. (1988) Plant Cell Physiol. 29, 761-769.

57. Janssen, M., Bathke, L., Marquardt, J., Krumbein, W. E., and Rhiel, E. (2001) Int. Microbiol. 4, 27-33. 
58. Pascal, A. A., Caron, L., Rousseau, B., Lapouge, K., Duval, J.-C., and Robert, B. (1998)

Biochemistry 37, 2450-2457.

59. Kühlbrandt, W., Wang, D. N., and Fujiyoshi, Y. (1994) Nature 367, 614-621.

60. Ruban, A. V., Pascal, A. A., Robert, B., and Horton, P. (2001) J. Biol. Chem. 276, 24862-24870.

61. Olaizola, M., Bienfang, P. K., and Ziemann, D. A. (1992) J. Exp. Mar. Biol. Ecol. 158, 59-74.

62. Brunet, C., Brylinski, J. M., and Lemoine, Y. (1993) Mar. Ecol. Prog. Ser. 102, 69-77.

63. Rmiki, N.-E., Brunet, C., Cabioch, J., and Lemoine, Y. (1996) Hydrobiologia 326/327, 407-413.

64. Ruban, A. V., Young, A. J., and Horton, P. (1993) Plant Physiol. 102, 741-750.

65. Horton, P., Ruban, A. V., and Wentworth, M. (2000) Phil. Trans. Roy. Soc. London B 355, $1361-1370$. 
Table 1: Pigment composition of dark-adapted CL and IL cells grown under an intensity of $40 \mu \mathrm{mol}$ photons. $\mathrm{m}^{-2} . \mathrm{s}^{-1}$, and of corresponding sucrose gradient fractions containing lightharvesting complexes (LHCF) and photosystems (PS).

\begin{tabular}{|c|c|c|c|c|c|}
\hline $\begin{array}{c}\text { Pigments } \\
(\mathrm{mol} / 100 \mathrm{~mol} \mathrm{Chl} a)^{a}\end{array}$ & CL cells & Major LHCF & PS II+LHCF & PS I+LHCF & Pellets \\
\hline Chl $c$ & $15.9 \pm 0.3$ & $24.8 \pm 1.0$ & $8.7 \pm 0.06$ & $5.8 \pm 1.0$ & $8.4 \pm 1.8$ \\
\hline Fucoxanthin & $68.4 \pm 3.0$ & $110.0 \pm 5.9$ & $47.3 \pm 3.2$ & $31.0 \pm 1.5$ & $52.0 \pm 3.4$ \\
\hline DD & $9.5 \pm 1.5$ & $9.6 \pm 2.3$ & $8.9 \pm 0.4$ & $10.5 \pm 0.7$ & $6.7 \pm 1.0$ \\
\hline DT & 0 & 0 & 0 & 0 & 0 \\
\hline B-carotene & $8.0 \pm 1.1$ & $1.8 \pm 0.2$ & $12.3 \pm 2.7$ & $15.1 \pm 1.8$ & $8.6 \pm 1.9$ \\
\hline $\begin{array}{c}\text { Pigments } \\
(\mathrm{mol} / 100 \mathrm{~mol} \mathrm{Chl} a)^{a}\end{array}$ & IL cells & Major LHCF & "PS II+LHCF & PS I+LHCF & Pellets \\
\hline Chl $c$ & $13.4 \pm 0.4$ & $19.9 \pm 1.2$ & $8.0 \pm 2.4$ & $5.1 \pm 0.4$ & $8.7 \pm 2.4$ \\
\hline Fucoxanthin & $65.5 \pm 3.5$ & $95.6 \pm 3.3$ & $46.0 \pm 3.3$ & $30.0 \pm 3.6$ & $51.4 \pm 0.2$ \\
\hline DD & $21.6 \pm 1.8$ & $27.6 \pm 3.1$ & $13.4 \pm 1.2$ & $13.2 \pm 1.7$ & $8.6 \pm 0.2$ \\
\hline DT & 0 & 0 & 0 & 0 & 0 \\
\hline B-carotene & $8.4 \pm 0.2$ & $2.3 \pm 0.7$ & $12.0 \pm 1.4$ & $14.3 \pm 2.2$ & $8.3 \pm 1.6$ \\
\hline $\begin{array}{l}{ }^{a} \text { Total Chl } a . \text { cell } \\
( \pm \mathrm{SD}) \text { are the averag }\end{array}$ & S $0.38 \pm 0$ & $\mathrm{pg}$ for $\mathrm{CL}$ & $\begin{array}{l}\text { and } 0.35 \pm \\
\text { asurements. }\end{array}$ & $05 \mathrm{pg}$ for $\mathrm{I}$ & cells; Data \\
\hline
\end{tabular}


Table 2: Pigment composition of the major LHCF fractions of IL and CL cells.
Pigments
IL cells
CL cells

$(\mathrm{mol} / 100 \mathrm{~mol} \mathrm{Chl} a)$

\begin{tabular}{lcc}
\hline Fucoxanthin & $110.0 \pm 5.9^{a}$ & $95.6 \pm 3.3^{a}$ \\
DD & $27.6 \pm 3.1$ & $9.6 \pm 2.3$ \\
Chl $c$ & $24.8 \pm 1.0^{b}$ & $19.9 \pm 1.2^{b}$ \\
DD + Fucoxanthin & $\mathbf{1 1 9 . 6} \pm \mathbf{6 . 0}^{c}$ & $\mathbf{1 2 3 . 2} \pm \mathbf{7 . 3}$ \\
Chl $c$ / Fucoxanthin & $\mathbf{0 . 2 2 5}$ & $\mathbf{0 . 2 0 8}$
\end{tabular}

Data ( \pm SD) are the average of three to five independent measurements; ${ }^{a, b}$ Student test (statistical test for mean values comparison): means are significantly different $(\mathrm{p}<0.05)$; ${ }^{c}$ Student test: means are not significantly different $(\mathrm{p}<0.05)$. 
Table 3: Pigment composition of illuminated IL cells $\left(20 \mathrm{~min}, 5300 \mu \mathrm{E} \cdot \mathrm{m}^{-2} \cdot \mathrm{s}^{-1}\right)$ and of corresponding sucrose gradient fractions containing light-harvesting complexes (LHCF) and photosystems (PS).

\begin{tabular}{lccccc}
\hline \multicolumn{1}{c}{ Pigments } & IL cells & IL cells & Major & PS II & PS I \\
$($ mol/100 mol Chl $a$ ) & dark-adapted & illuminated & LHCF & +LHCF & + LHCF \\
\hline Chl $c$ & 13.0 & 13.2 & 18.2 & 8.9 & 4.4 \\
Fucoxanthin & 68.0 & 66.7 & 93.2 & 55.6 & 27.2 \\
DD & $\mathbf{2 0 . 7}$ & $\mathbf{9 . 1}$ & $\mathbf{9 . 3}$ & $\mathbf{7 . 7}$ & $\mathbf{1 0}$ \\
DT & $\mathbf{0}$ & $\mathbf{1 3 . 9}$ & $\mathbf{1 9 . 1}$ & $\mathbf{6 . 0}$ & $\mathbf{6 . 3}$ \\
B-carotene & 8.5 & 8.4 & 2.1 & 10.6 & 15.4 \\
\hline DD+DT & $\mathbf{2 0 . 7}$ & $\mathbf{2 3 . 0}$ & $\mathbf{2 8 . 4}$ & $\mathbf{1 3 . 7}$ & $\mathbf{1 6 . 3}$ \\
DED $^{a}$ & $\mathbf{0}$ & $\mathbf{6 0}$ & $\mathbf{6 7}$ & $\mathbf{4 4}$ & $\mathbf{3 9}$ \\
\hline
\end{tabular}

${ }^{a}$ DED: de-epoxidation degree (in \%): DT/(DD+DT) x 100 


\section{FIGURE LEGENDS}

FIGURE 1: A- $77 \mathrm{~K}$ absorption spectra of CL (dotted line) and IL (continuous line) cells. The main pigment contributing to each band (Chl, chlorophyll; $\beta$-car, $\beta$-carotene; DD, diadinoxanthin, Fx, fucoxanthin) and the absorption peak of DD $(495 \mathrm{~nm})$ are indicated. The difference spectrum IL cells minus CL cells is the trace at the bottom part of the panel (it was multiplied by three). B- $77 \mathrm{~K}$ excitation spectra of the fluorescence emission at $687 \mathrm{~nm}$. The arrow indicates the excitation peak of DD. All spectra are normalized to $667 \mathrm{~nm}$; the minimum value at $600 \mathrm{~nm}$ is taken as the origin of the fluorescence spectra.

FIGURE 2: A- Distribution of the three LHCF bands on the sucrose gradient after solubilization of the thylakoids membranes by a mild detergent and centrifugation. B- Repartition of the total Chl $a$ loaded onto the gradient. C- Comparison of the amount of DD present in the different bands; CL (white boxes) and IL (black boxes) cells. Data $( \pm \mathrm{SD})$ are the average of three to four independent measurements.

FIGURE 3: $77 \mathrm{~K}$ absorption spectra of the three LHCF fractions isolated on sucrose gradient for the two types of cells (CL cells, top and IL cells, bottom): the 'major' LHCF (continuous line), and the two LHCF associated with PS II (dotted line) and PS I (dashed line), respectively. All spectra are normalized to $667 \mathrm{~nm}$.

FIGURE 4: A- $77 \mathrm{~K}$ emission fluorescence spectrum of Chl $a$ excited at $440 \mathrm{~nm}$ of the major LHCF fraction of CL cells (dotted line) and IL cells (dashed line). Spectra are normalized to $678 \mathrm{~nm}$. B- $77 \mathrm{~K}$ excitation spectra of Chl $a$ emission at $678 \mathrm{~nm}$ of whole IL cells (continuous line) and the 'major' LHCF fraction of CL cells (dotted line) and IL cells (dashed line). Spectra are normalized to $667 \mathrm{~nm}$; the minimum value at $600 \mathrm{~nm}$ is taken as the origin.

FIGURE 5: $77 \mathrm{~K}$ absorption of the 'major' LHCF fraction of dark-adapted (dotted line) and illuminated

(continuous line) IL cells. Spectra are normalized to $667 \mathrm{~nm}$. Illumination at $5300 \mu \mathrm{mol}$ photons.m ${ }^{-2} \cdot \mathrm{s}^{-1}$ for 20 min induced a $67 \%$ de-epoxidation of DD into DT (see Table 3). Three absorption bands (438, 
475 and $508 \mathrm{~nm}$ ) due to the conversion of DD in DT during light exposure are visible in the difference spectrum (illuminated cells minus dark-adapted cells, bottom dashed line). 
Figure 1 - Lavaud, Rousseau and Etienne
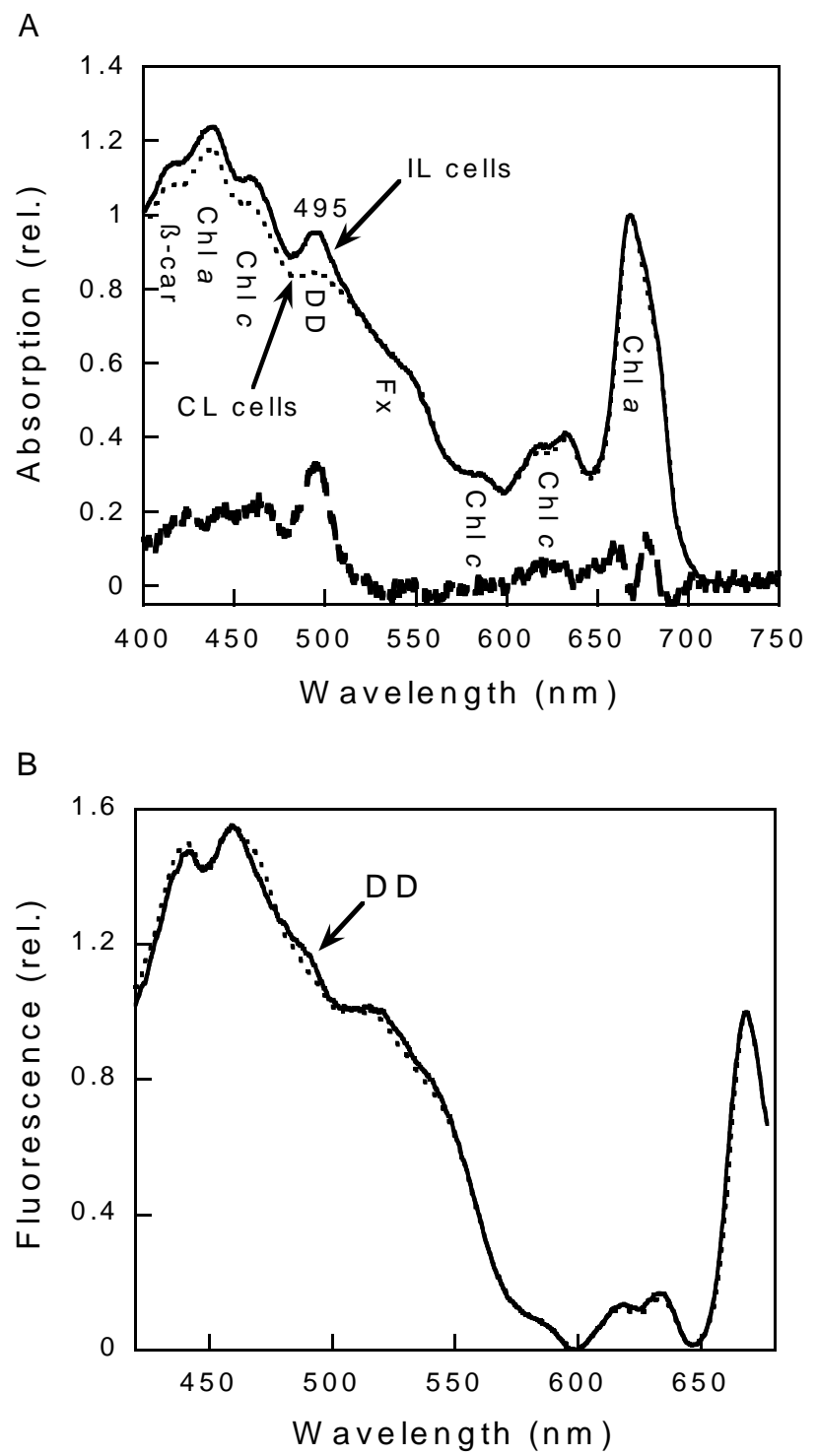
Figure 2 - Lavaud, Rousseau and Etienne
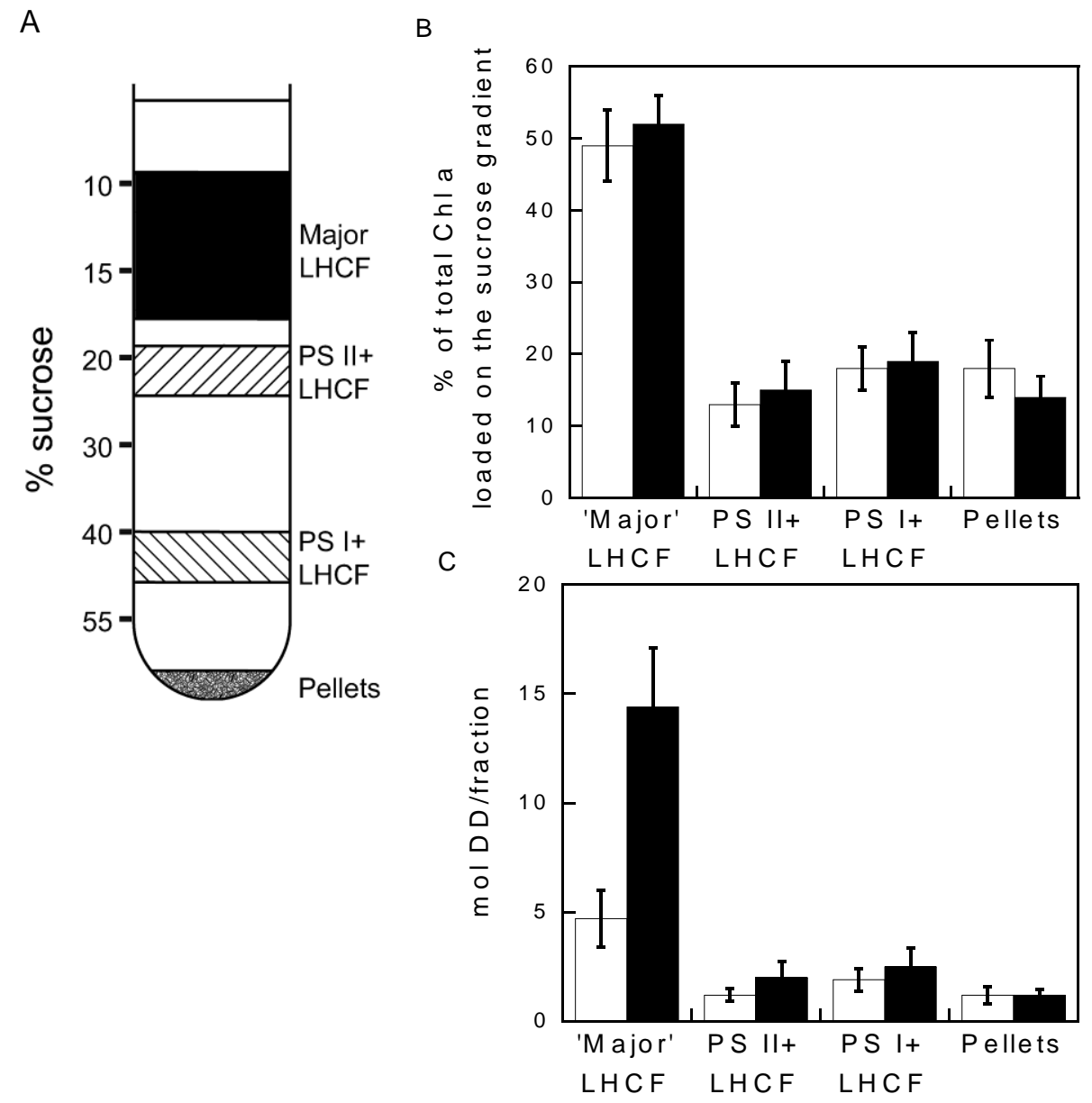
Figure 3 - Lavaud, Rousseau and Etienne
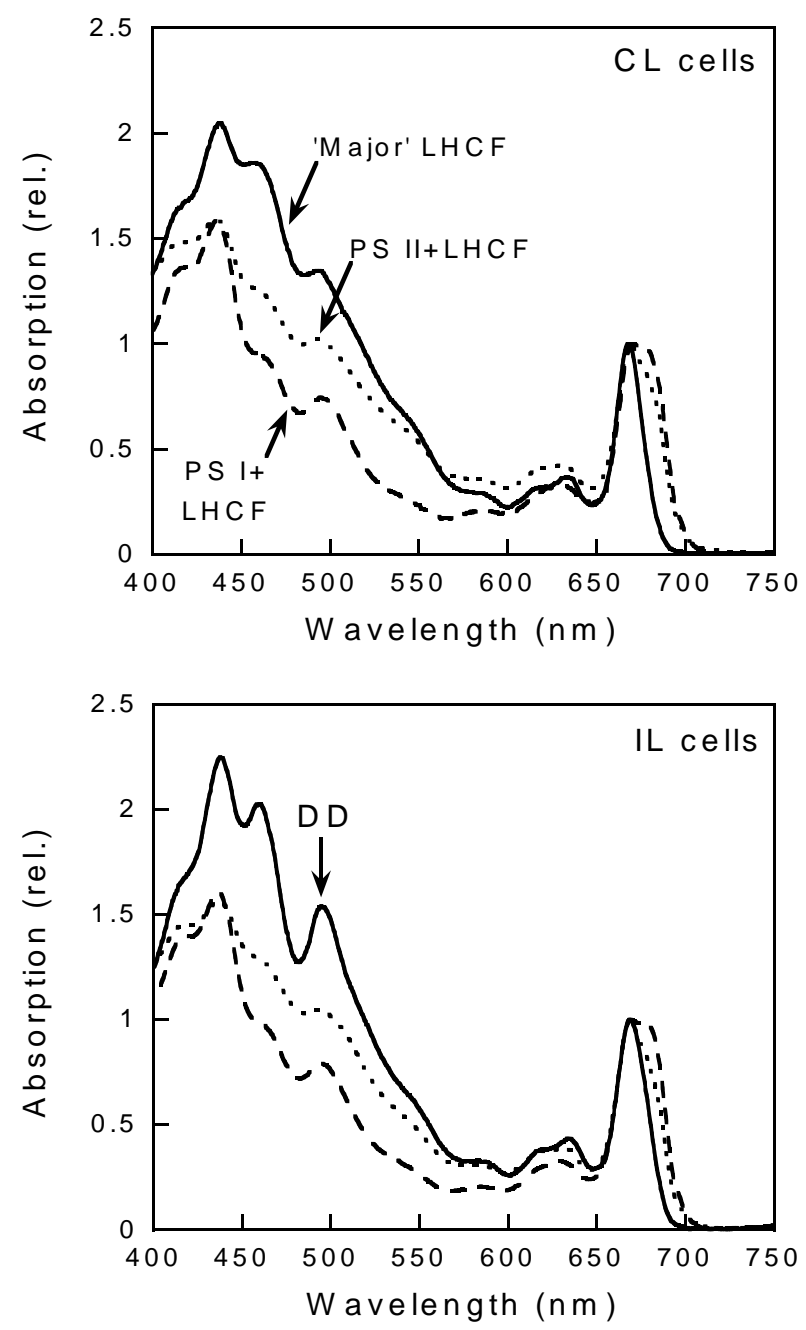
Figure 4 - Lavaud, Rousseau and Etienne

A
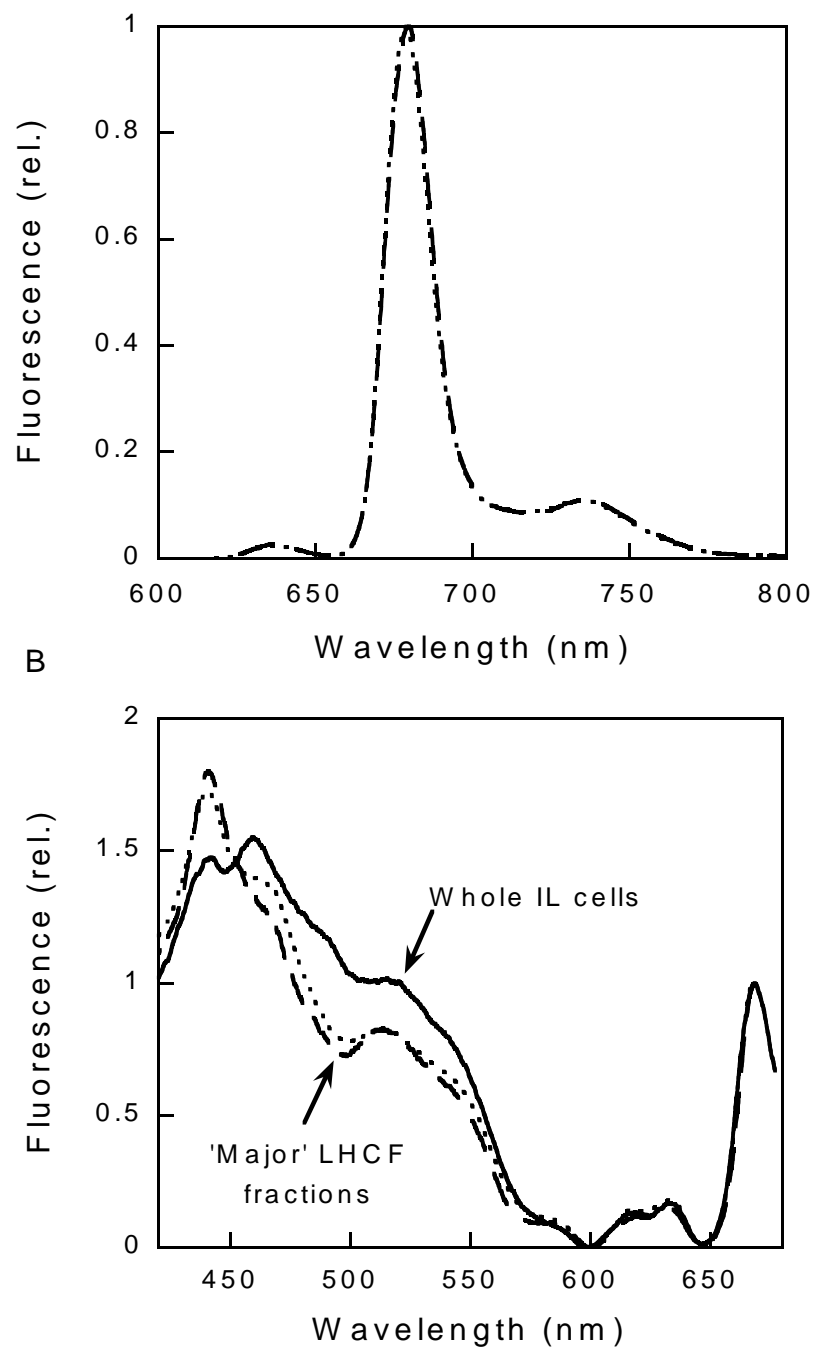
Figure 5 - Lavaud, Rousseau and Etienne

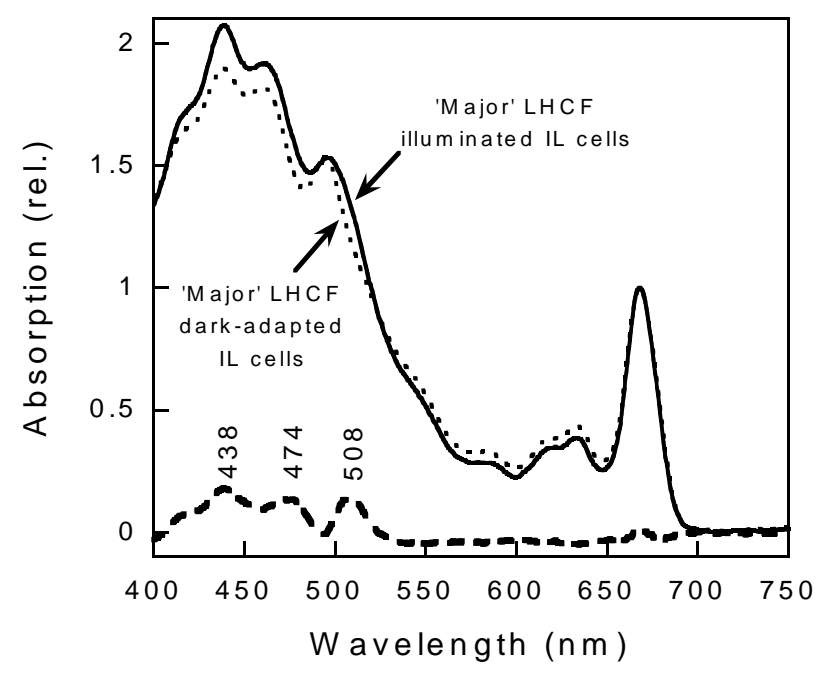

